\title{
Cochin - The Emerging Silicon Valley of India: Requirement of Right Policies
}

\author{
V. Anoop Kumar ${ }^{1}$, Dr. R. Ganesan ${ }^{2}$ \\ ${ }^{I}$ (Research Scholar, Bharathiar University, Coimbatore. Asst. Professor, Dept. of Management Studies, P.A. \\ College of Engineering and Technology, Coimbatore, India) \\ ${ }_{2}^{2}$ (Principal, Sri Venkateshwara College of Computer Applications and Management, Coimbatore, India)
}

\begin{abstract}
Software industry is acknowledged as an important engine of economic growth for many developing and under developed countries. Software development is a service that is both labour and knowledge-intensive. Nowhere are human resources as critically important as in the software sector. Human resources are not only the drivers and principal value-creators of the output of this industry; they are also the intellectual capital or the infrastructure investment. Therefore, attracting, training, retaining and motivating employees are the critical success-determinants of this industry.

The comparative study and analysis of job satisfaction conducted at the two metros of Cochin and Bangalore reveals that the software professionals working at Cochin and its suburbs are not satisfied with their current job and its allied services. It shows that the satisfaction level of software professionals working at Bangalore is significantly high compared to Cochin, with respect to Nature of Job, Wages and Perks. The sub scales such as Pay, Fringe Benefits, Contingent Rewards, Operating Conditions and Communication also supported the same.

This research paper also provides an analysis of the human resource issues facing in the Indian software industry and also tries to give an insight to the policy makers and sector players to develop right strategies so that Cochin also will be successful in meeting global competition.

We have better opportunities than many other developing or even developed countries with regard to human resources. If there is better policy and implementation to solve the HR challenges discussed here, there is no doubt that Cochin will become one of the emerging Silicon Valley of India.
\end{abstract}

Keywords: Policy, Manpower, Software, Motivation, Satisfaction.

\section{Introduction}

The success of any business or industry mainly depends on the workforce they employed with that. The IT industry is much more in the same line. Here, this study aims to compare the level of job satisfaction among the software professionals working in the IT sector of Bangalore and Cochin. The factors affecting job satisfaction such as wages and perks, nature of job, supervision, cooperation from coworkers, promotion opportunities, stress and tension etc. were focused to reach the level of job satisfaction.

Software industry is acknowledged as an important engine of economic growth for many developing and under developed countries. Software development is a service that is both labour and knowledge-intensive, and thus an important aspect of related policy is concerned with the provision of appropriately educated and trained human resources in sufficient quantity.

This paper provides an analysis of the human resource issues facing in the Indian software industry and also tries to give an insight to the policy makers and sector players to develop right strategies to win the global competition in this sector.

The "human resources are the greatest asset" is a general statement, often heard in corporate boardrooms is true in most of the industries. However, nowhere are human resources as critically important as in the software sector. Human resources are not only the drivers and principal value-creators of the output of this industry; they are also the intellectual capital or the infrastructure investment. Therefore, attracting, training, retaining and motivating employees are the critical success-determinants of the software industry.

With the ongoing 'slowdown' in Europe and US, the software industry is again in limelight with its key HR issues. The industry is employee oriented. The employees are its key resource. Their competence and enthusiasm plays a great role in success of the industry.

Software is a wealth and job creating industry, which has in just a few years, grown to US \$ 1 trillion, employing millions of professionals worldwide. The Indian software industry has burgeoned, showing a nearly $50 \%$ compounded annual growth rate over the recent years. Being a knowledge-based industry, a high intellectual capital lends competitive advantage to a firm. Intellectual capital comprises human capital and any created bit of knowledge or expertise. With a global explosion in market-opportunities in the software industry, the shortage of manpower both in numbers and skills is a prime challenge for HR professionals. The related 
issues are varied indeed: recruitment of world-class workforce and their retention, compensation and career planning, technological obsolescence and employee turnover.

\section{Methodology}

This study used explorative design. The geographical area of the study limited to the city and suburbs of Cochin and Bangalore. The targeted population was the software professionals working in the IT Industry of these cities. A total of 400 professionals taken as sample for this study (200 each from Cochin and Bangalore). The job satisfaction scale developed by Mr. Paul E. Specter, Dept. of Psychology, University of Florida was used to assess the level of job satisfaction among the target group. Primary data was collected directly from the software professionals. The collected data entered into a master chart with the help of computer software Excel and analysis done by using SPSS version 11.0. The statistical tests namely T tests, ANOVA, Chi -square test etc. were administered to get the reliable results.

\section{The Study results}

\subsection{Socio -economic status of the software professionals.}

The male employees come to $57 \%$ of the total sample. The women employment is high at Cochin (43\%) compared to Bangalore (38.5\%). The following table explains the same in detail.

Table 3.1

\begin{tabular}{|l|l|l|l|l|}
\hline \multirow{2}{*}{ Location and Gender } & \multicolumn{2}{|l|}{ Gender } & \multirow{2}{*}{} \\
\cline { 3 - 5 } Cochin & Count & Male & Female & Total \\
\hline \multirow{3}{*}{ Bangalore } & \% within Location & 114 & 86 & 200 \\
\cline { 2 - 5 } & Count & 57 & 43 & 100 \\
\cline { 2 - 5 } & $\%$ within Location & 123 & 77 & 200 \\
\hline
\end{tabular}

The mean age of software professionals is less at Cochin (25 years) than Bangalore (28 years). The entire software professional's atleast have a bachelor degree. Among the total sample, $26.5 \%$ have PG degree and another $34.5 \%$ have technical education. The educational status is more or less the same both at Bangalore and Cochin. The following chart compares the educational status of software professionals.

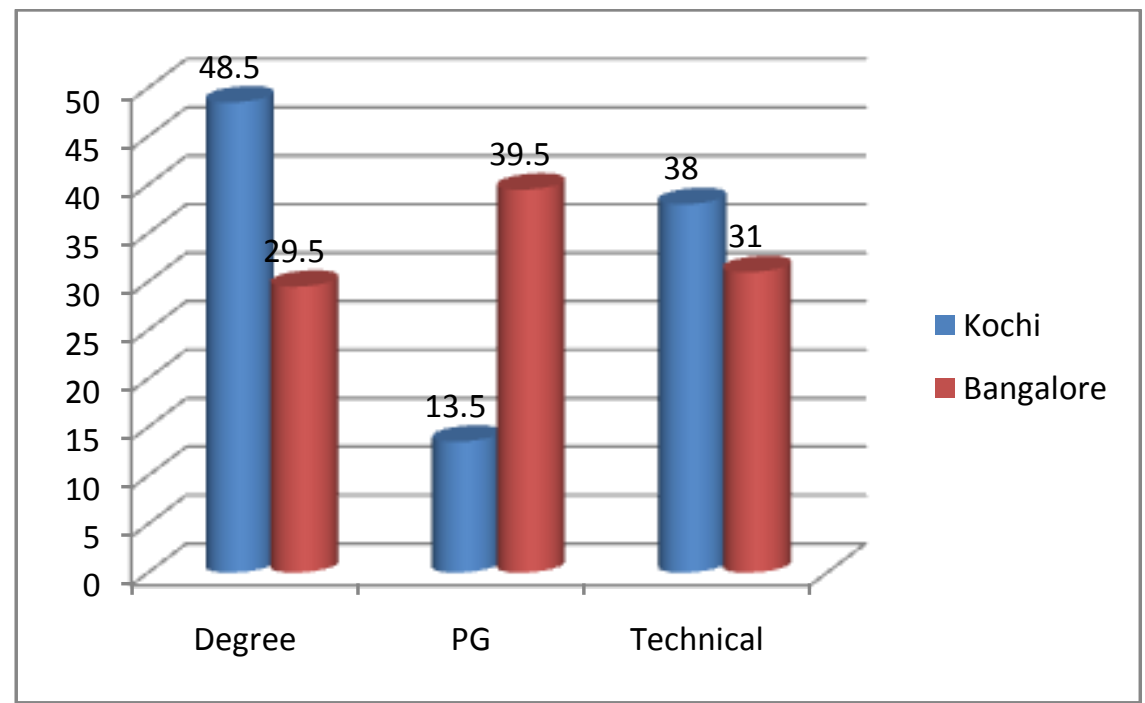

Fig.3.1

Comparison of educational status

Out of the total sample, the least income professional gets rupees 0.96 lakh/annum. It goes up to 16.8 lakh/annum for high return group. The mean annual income is rupees 345216/-. The range of income is high at Bangalore compared to Cochin. The mean annual income of Cochin professionals is rupees 288348/- and rupees 402072/- at Bangalore. 


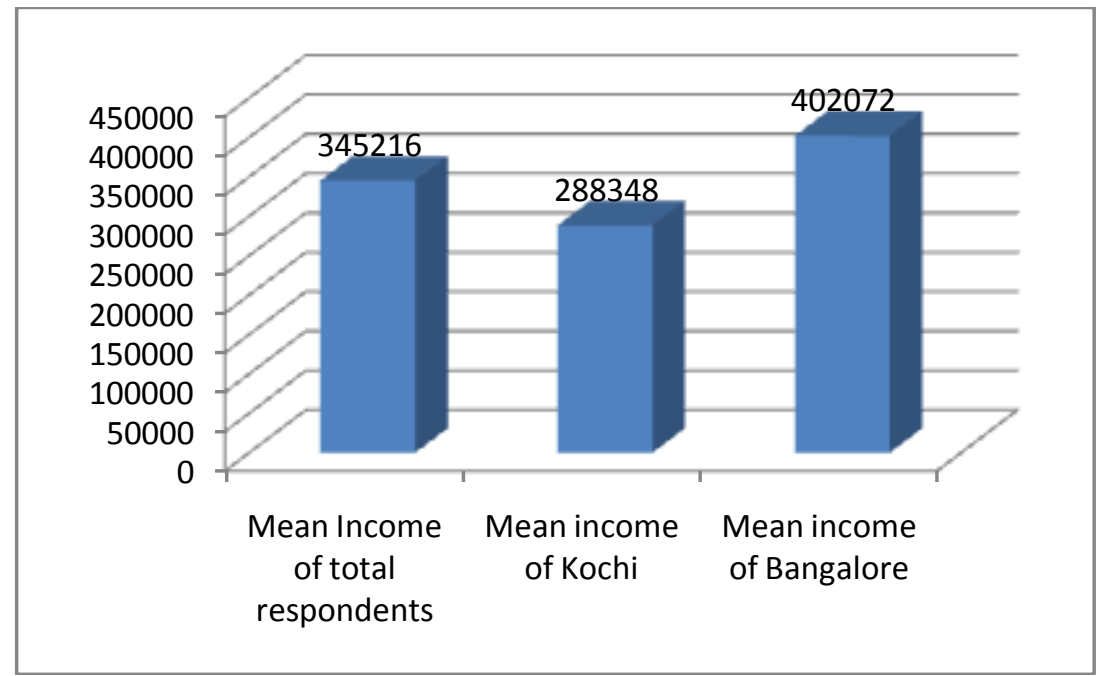

Figure: 3.2 Mean annual income of software professionals

Here the majority of the less income group works at Cochin.

The work experience in this industry ranges from 3 months to 96 months. The number of less experienced professionals is high at Cochin compared to Bangalore. The mean value of Cochin is 21 months and Bangalore is 37 months.

\subsection{Assessment of Job Satisfaction}

\subsubsection{Pay and Nature of Work}

The study results show that the satisfaction level of software professionals from Bangalore is significantly high than the Cochin people with respect to nature of job, wages and other perks. The mean value of the payment score is high at Bangalore (17.14) than Cochin (13.88) and it is statistically significant $(\mathrm{P}<.05)$. The results on the nature of work also shows the level of satisfaction is high at Bangalore but statistically it is not significant ( $\mathrm{P}>$.05). The following table shows the detailed description of the different sub scales score and test results.

Table No 3.2

\begin{tabular}{|c|c|c|c|c|}
\hline & Location & Mean & $\begin{array}{c}\text { Std. } \\
\text { Deviation }\end{array}$ & P value \\
\hline \multirow{2}{*}{ PAY } & Cochin & 13.88 & 2.953 & \multirow{2}{*}{0.00} \\
\cline { 2 - 4 } & Bangalore & 17.14 & 3.773 & \\
\hline \multirow{2}{*}{ Nature of work } & Cochin & 17.13 & 3.848 & \multirow{2}{*}{0.43} \\
\cline { 2 - 4 } & Bangalore & 18.55 & 3.990 & \\
\hline
\end{tabular}

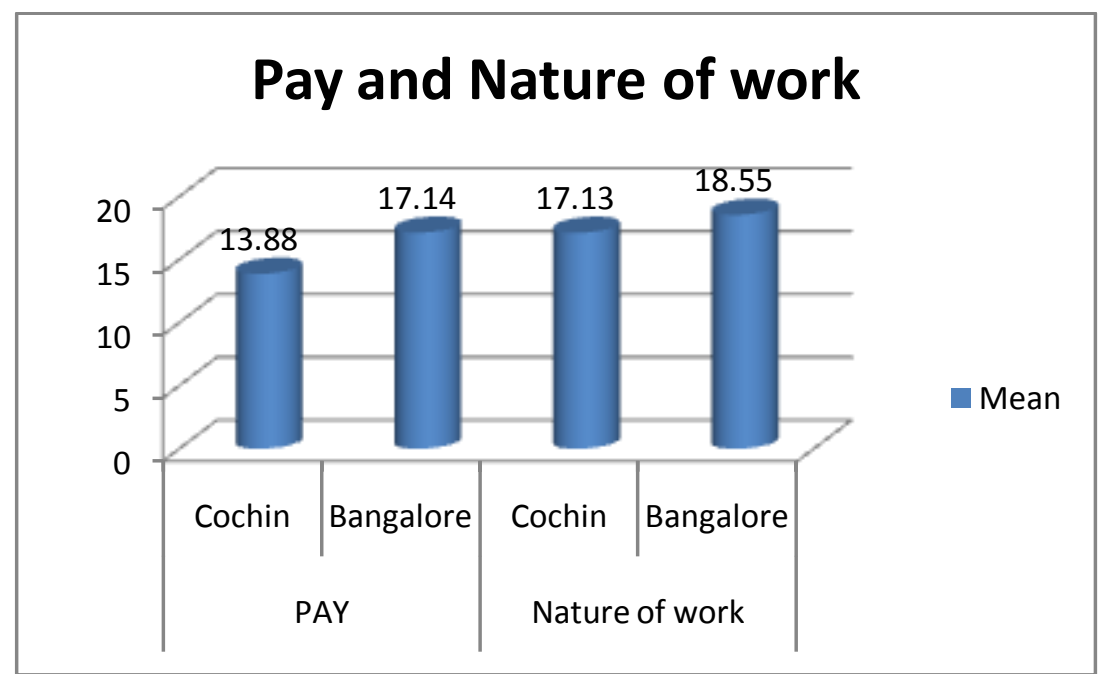

Fig.3.3 Comparison of level of satisfaction with regard to pay and nature of work 


\subsubsection{Supervision and Cooperation from coworkers}

The result shows that there is no significant difference in the satisfaction level with regards to supervision and cooperation from coworkers among the software professionals of Bangalore and $(\mathrm{P}>.05)$, eventhough there is a slight difference in the mean value. The mean value of Supervision score is high at Bangalore (19.86) than Cochin (16.40).

Table No 3.3

\begin{tabular}{|c|c|c|c|c|}
\hline & Location & Mean & SD & P value \\
\hline \multirow{2}{*}{ Supervision } & Cochin & 16.40 & 3.373 & \multirow{2}{*}{0.65} \\
\cline { 2 - 4 } & Bangalore & 19.86 & 3.717 & \\
\hline \multirow{2}{*}{ Coworkers } & Cochin & 16.45 & 3.184 & \multirow{2}{*}{0.74} \\
\cline { 2 - 4 } & Bangalore & 20.58 & 3.193 & \\
\hline
\end{tabular}

\subsubsection{Career development and promotional aspects}

The study results shows that the level of satisfaction towards career development and promotional aspects, it is comparatively high among the Bangalore professionals than Cochin professionals but statistically it is not coming to a significant level $(p>.05)$. The following figures analyses the status.

Table No. 3.4

\begin{tabular}{|c|c|c|c|c|}
\hline & Location & Mean & SD & P value \\
\hline Promotions & Cochin & 16.55 & 2.678 & \multirow{2}{*}{0.78} \\
\hline & Bangalore & 16.84 & 2.633 & \\
\hline Career development & Cochin & 14.74 & 4.364 & 0.00 \\
\hline & Bangalore & 18.61 & 3.697 & \\
\hline
\end{tabular}

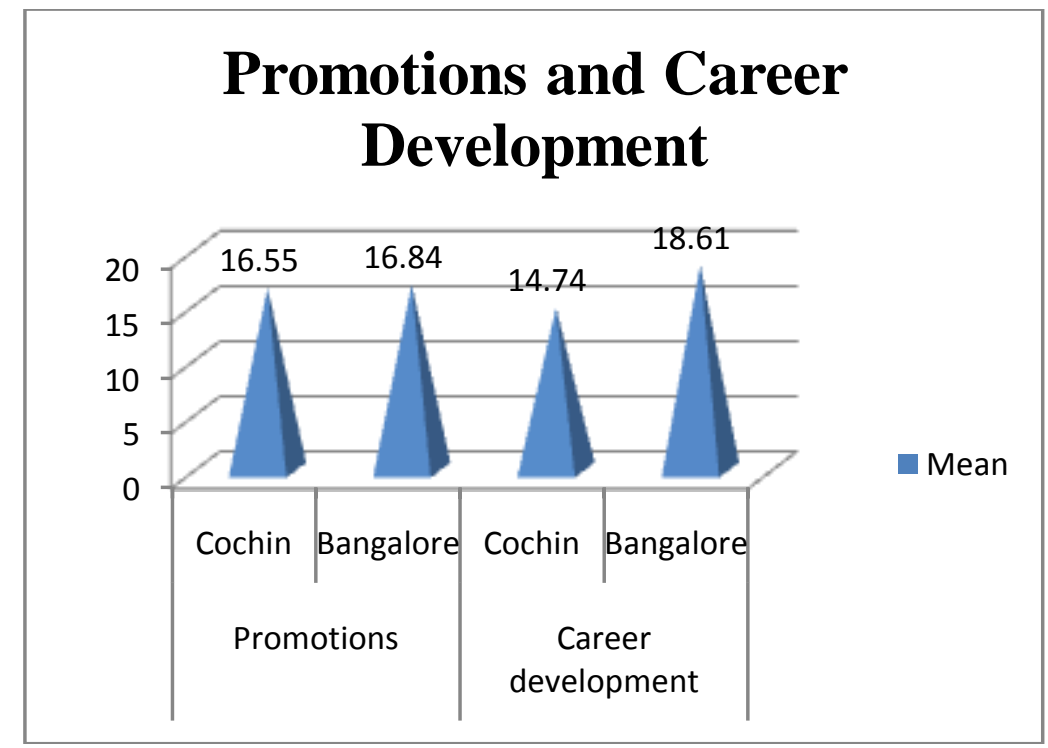

Fig.3.4.

\subsection{The level of job satisfaction: Bangalore and Cochin.}

The study reveals that there is a significant variation in the job satisfaction level of software professionals of Bangalore and Cochin $(\mathrm{P}<.05)$. The mean score of 9 sub scales also supported the same (Bangalore $=156.26 \&$ Cochin=137.13). The people from Bangalore is highly satisfied than that of Cochin. The sub scales such as Pay, Fringe Benefits, Contingent Rewards, Operating Conditions and Communication also supported to the same $(\mathrm{P}<.05)$.

The other sub scales such as Qualitative Overload, Role Conflict, Autonomy, Lack of Challenges, Interpersonal Relationships, Promotions, Victimizations, Alienation, Perceived Status, Strong Working 
Conditions, Grievance Redressal, Rigid Rules, Inadequate Pay, and Schedule of Working Time etc. are not statistically significant $(\mathrm{P}>.05)$.

\section{Requirement of Software Professionals}

Coping with the Demand-Supply Gap shortage of IT professionals is global in nature and not peculiar to the Indian software industry alone. W. Strigel, founder of Software Productivity Centre Inc. (1999) has projected the shortage of software professionals to be 1.5 million by 2015. In fact, a survey reports that 75 per cent of US companies planned to reengineer their applications using newer technologies, but found that 72 per cent of their existing staff lacked the skills needed in these technologies, and 14 per cent were not even retrainable.

Table 4.1 Annual demand for IT professionals in India

\begin{tabular}{|c|c|c|c|c|c|c|c|c|c|c|c|c|c|}
\hline Year & 1986 & 1991 & 1996 & 2001 & 2002 & 2003 & 2004 & 2005 & 2006 & 2007 & 2010 & 2012 & 2015 \\
\hline number & 2000 & 20000 & 40000 & 90000 & 115000 & 150000 & 195000 & 250000 & 300000 & 340000 & 370000 & 400000 & 500000 \\
\hline
\end{tabular}

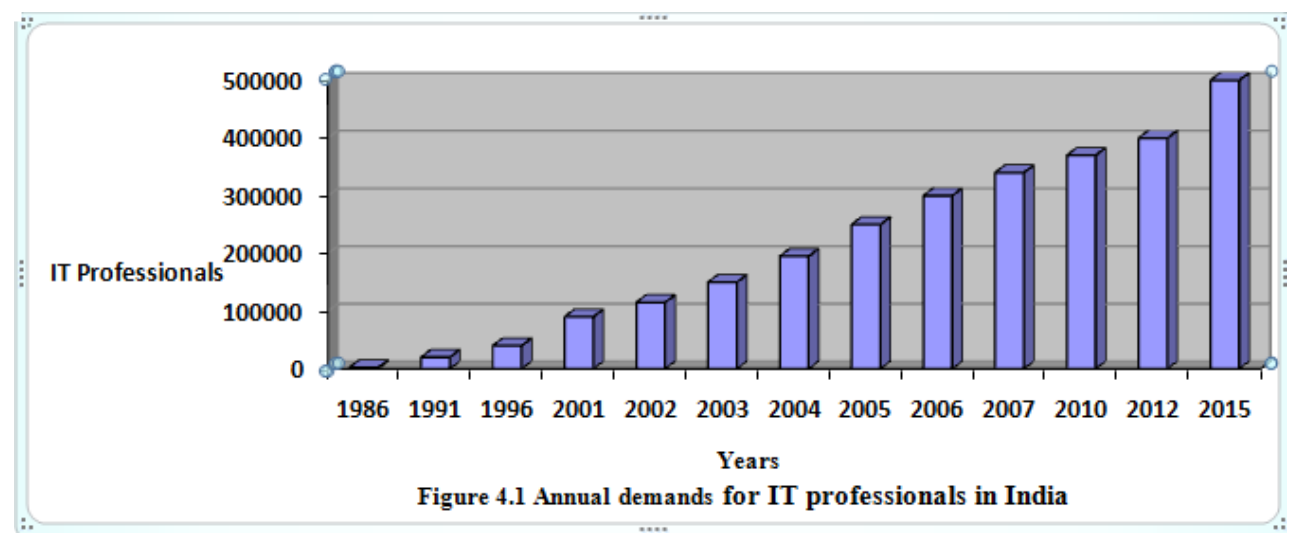

\subsection{The availability of human resources}

The available estimates indicate that about 200,000 engineering graduates and diploma holders are produced in India every year. Of these, according to NASSCOM analysis, about 90,000 are IT professionals, and 70,000 enter the workforce. Another 60,000 non-IT professionals to join the industry, making for a total of about 130,000 fresh entrants. This number is clearly inadequate to meet the needs, as projected over the next five years.

Fortunately, over the last few years, a great deal of additional capacity has been created in technical education. Apart from the expansion in existing institutions, many private colleges have been set up. A recent government estimate indicates that the intake capacity for technical education has increased from 134,000 to 386,000 in the last 8 years. As a result of this three-fold increase in admissions, there should be a nearlyequivalent rise in output over the next few years. Further growth through new institutions and expansion of present ones is also likely. This, and the fact that over 1.5 million other graduates are available every year (including about 500,000 in Science and Mathematics), should ensure that the challenge of numbers is met.

\subsection{Lack of motivation and retention}

Even though some companies given priority to retention and motivation of software personnel, still the lack of retention and motivation are major HR concerns. People have observed that the average tenure for an IT professional is less than three years. Further, the use of new technologies, the support of learning and training, and a challenging environment ranked higher than competitive pay structures as effective retention practices. A recent survey of 1028 software professionals from 14 Indian software companies, showed that while the professional gave importance to personal and cultural job-fit, HR managers believed that the key to retention was salary and career satisfaction. Money was a prime motivator for 'beginners', but for those into their third or fourth jobs, their value-addition to the organization was more important. Monetarily, offering 'the best salaries in industry' is the minimum every company is doing, apart from performance-based bonuses, long-service awards, and stock options. Many organizations frequently conduct employee satisfaction and organization climate surveys, and are setting up Manpower Allocation Cells (MAC) to assign 'the right project to the right 
person'. In fact, some are even helping employees with their personal and domestic responsibilities to satisfy \& motivate their workforce.

\subsection{Quality of the manpower}

One of the major issues facing in the software industry is the retention and up gradation of the quality and skill of the existing manpower. It is true that some Indian institutions (the IITs and IIMs, in particular) have established an enviable world-wide reputation for turning out top-quality professionals. However, the average engineering graduate is hardly of world-class, and the average non-technical graduate is of distinctly inferior quality. The curriculum in most universities is obsolete, as are the texts. The quality of faculty and of infrastructure (laboratories, equipment, etc.) is poor, and the pedagogic methods and materials are completely inadequate.

One of the comments often heard about Indian Software professionals is that their skills in their core function are excellent, but that they lack other capabilities. As the industry grows, it is essential that IT professionals be more rounded personalities. In particular, it is important that they improve articulation - both oral and written - become a little more aggressive (though not abrasive) and develop social skills. As the focus of the work moves from mere code-writing to consulting, problem-definition, system integration and project management, there is need for adding other capabilities to the repertoire of technical skills. The development of such soft skills must become a priority for IT companies

Skills in marketing, team-work etc are essential skill requirement in software industry. With more complex projects, efficient delivery requires smooth team-work. The added requirement now is that the teams are often international.

\subsection{Attracting and retaining talent}

The software industry has, during the last decade, been probably the most attractive sector to work in. It has, therefore, been able to get the best talent. The challenge now is to safeguard and build on this prime position. Attractive compensation, challenging assignments, good working conditions and growth opportunities are amongst the main determinants of where talent gravitates, along with the indefinable "glamour value" of an industry or a specific company. Taking care of these parameters is a necessary task for the software industry.

Retaining talent is a major challenge for companies, especially in a growth boom. However, the attrition rate for the industry as a whole, (i.e., people moving out of IT into other industry sectors) has been low. Even so, this will continue to be a challenge at both levels: for the individual company and the industry.

The IT industry has provided an excellent physical work-environment. It needs to continue to be a leader in providing these facilities, including food, fitness and sports facilities. While these "add-ons" are not inconsequential, job satisfaction through challenging, cutting-edge assignments, and substantial growth prospects are definitely major determinants for retention. Providing these is critical, and is of particular importance in the ITES/BPO sector, where attrition rates tend to be high for just these reasons.

Compensation is probably the single most important parameter in most cases. The challenge here is to provide an attractive package in the context of rising expectations, and yet minimize overall cost escalation. In this situation, poaching people from other companies by offering higher pay packages is self-defeating for the industry as a whole. An important corrective action lies in ensuring an ever-growing and sufficiently large supply pipeline of fresh entrants.

\section{Suggestions to develop and practice right policies}

The issues in the Human resource management of the software industry shall be addressed by both the governmental policies as well as the big players in the industry.

If a company spends a large part of its time in motivating the employees and its problems, then the Software Company would not run a long way. Now-a-days, top Software Companies in India have adopted a new way policy that of an Employee Manual Builder. It saves the company in almost thousand dollars spent on employee recruitment as well and many other internal problems arrived in a Software Outsourcing Company.

There are ample of texts and guidance available in the online sites of Google pages, and many of the Yahoo and MSN sites. There are many comments given by the various authors, who are usually running the Top Software Outsourcing Companies of India, sharing their views and experience regarding the HR policies and carried on personnel management work. They talk about many experiences felt and experienced when in conversed with project leaders, the IT managers and the employee relationship. Such suggestions and issues help the Software Outsourcing Company to develop a reader-friendly manual which spends less time in handling personnel issues and more time in running the company or any department.

It is essential that software industry work with academic institutions in the continuous updating of syllabi and ensuring relevance. Industry could also provide attachments and internships to both students and 
faculty so as to create greater motivation. Well-funded chairs and research grants will serve to attract and retain good faculty.

Effective Communication is regarded as most accepted way of handling any tough experience in the software industry. The expectations of the employees are taken into consideration, and the policies are improved upon in the top software companies in India. There are written employee handbooks which will re-vamp to a great extend the morale and increase productivity of the employees as well as keeping the outsourcing company out of the legal restrictions. The book also states code of conducts to be maintained in software company, that each and every employee needs to follow.

5.1 Good language skills (particularly English, but potentially also in Spanish, French, German and Japanese) is one of the requirements for booming the sector, and one of the opportunities for the education system, including private training institutions. So far, this industry has been concentrated in just 4 or 5 of the metros. Its long-term growth, however, depends upon moving large parts of its operations to smaller cities. One of the major challenges is to find enough people with good language skills in these cities. This is potentially a major problem for the whole industry. So our policy makers shall give prominent importance to address these issues.

\subsection{Building Global Organizations}

As Indian IT companies grow, and enter new geographies, they will need to become truly international. Their delivery models too will need this, as customers push for multi-country disaster recovery sites. Also, they will need to increasingly tap the best talent from whichever country it is available. These factors, and the possibility of inorganic growth by acquiring foreign companies, will all dictate the increasing globalisation of Indian IT companies. To do this successfully, they will have to modify and adapt their structure and organisational culture to be able to absorb and draw the best from professionals of different nationalities and cultures. A basic change in mind-set is needed for this to happen successfully, and this is a major challenge for home-grown, very "Indian" companies: how to transform into global corporations without losing the positive values and culture that they have developed.

\section{Conclusion}

The Indian software export market is in the right path and the domestic software market has moved beyond single digit growth to enter the double-digit phase over the past two years. The domestic market, which has traditionally lagged behind the exports segment, has shown promising growth in the recent years, emphasizing need for the software industry to re-look at this market and the potential business opportunities it offers. The domestic market growth was stimulated by a drop in prices, resulting in larger volume growth compared to last year.

There are so many Keralites working in the IT sector worldwide. Majority of them try to find out an opportunity to return. But the prevailing pay and other aspects of job in IT sector is not much motivating them to do so. The IT Industry also needs to change their practices to motivate them for better results. The policy makers also need to change the policies accordingly.

We have better opportunities than many other developing or even developed countries with regard to human resources. If there is a better policy and implementation to solve the HR challenges discussed here, there is no doubt we will become the masters in the software industry globally.

\section{Acknowledgements}

This research paper owes a lot to the valuable information and feedback given by various software professionals and firms in the metros and suburbs of Cochin and Bangalore. Also, remembering the facilitations provided by IIM-B, IIM-K and Cochin University of Science and Technology authorities for their feedback, guidance and references. Above all, the blessings of the Almighty.

\section{Books}

\section{References}

[1] Andy Bilson and Sue Ross., "Social work management and practice, Systems and principles, Jessica Kingsly publishers Ltd., London - 1999

[2] Atkinson, J.W. (1964) An introduction to motivation. New York: D. Van Nostrand.

[3] Azrin, N.H. \& Holz, W.C. (1966) Punishment. In W.K. Honig (Ed.) Operant behaviour: Areas of research and application. New York : Appleton-Century - Crofts.

[4] A Handbook of Human Resource Management Practice Armstrong, Michael (2006). (10th edition ed.). London: Kogan Page

[5] Barash, D.P., (1978) Sociobiology and behaviour, New York Elsevier.

[6] Capaldi,.e.J. (1967) A sequential hypothesis of instrumental learning. In. K.W. Spence \& J.T. Spence (Eds). The psychology of learning and motivation (Vol. 1) New York: Academic.

[7] Frank Ostraff, The Horizontal Organization, Oxford University Press, New York, 1999.

[8] Hull, C.L. (1943). Principles of behaviour. New York : Appleton-Centruy-Crofts. 


\section{Journals}

[1] The journals -Contemporary management Research; Bharathedasan Institute of Management, Thiruchirapply, India, Vol. 1, 2007 March.

[2] I.I. M.B.- Management Review, Bangalore, India, .2009

[3] Synthesis. B.L.s. Institute of Management, India 2006

[4] Management and Laber studies', X.L.R.I Jemshadpur, India - 2009 Nov.

[5] Vikalpa - The journal of Dicision makers Indian institute of Management, Ahmadabad, India, 2010.

[6] Organisational Behaviour and Human performance, Vol. 3. Nov.

[7] Harvard Business Review, July, August 1999.

[8] Psychological Review, Vol. 9. 1959 June, New York, Wiley.

[9] Young.P.T. (1959) The role of affective processes in learning and motivation. Psychological Review, 66, $104-125$. 